\title{
Five High-Cost Patient Groups
}

\author{
Hemal K. Kanzaria, MD MSC ${ }^{7}$ and Jerome R. Hoffman, MA MD ${ }^{2}$ \\ 'Department of Emergency Medicine, University of California San Francisco, San Francisco, CA, USA; ${ }^{2}$ School of Medicine, University of California \\ Los Angeles, Los Angeles, CA, USA.
}

J Gen Intern Med 32(9):966

DOI: $10.1007 / \mathrm{s} 11606-017-4106-\mathrm{y}$

(c) Society of General Internal Medicine 2017

\section{Dear Editor,}

We were delighted to read the thoughtful letter from Drs. Westfall and Griswold, with which we could not agree more. As one of them has previously argued, ${ }^{1}$ population health is far more likely to benefit if we focus less on individual high-utilizers, and more on the underlying systemic social and economic problems that create "cold spots" where health outcomes for entire communities inevitably suffer. Healthcare can of course be invaluable in ameliorating disease in individuals, but improving the health of the population requires a fundamental shift in approach. Only by focusing far more attention - and far more resources - on the social determinants of health will we be able both to reduce health inequities and to improve outcomes, not merely for individual patients - regardless of whether or not they are frequent users - but also for the public health overall.

Corresponding Author: Hemal K. Kanzaria, MD MSc; Department of Emergency Medicine, University of California San Francisco, San Francisco, CA, USA (e-mail: Hemal.Kanzaria@ucsf.edu).

\section{Compliance with Ethical Standards:}

Conflict of Interest: In the past 36 months, Dr. Kanzaria has been a consultant for RAND Health and Castlight Health.

\section{REFERENCES}

1. Westfall JM. Cold-spotting: linking primary care and public health to create communities of solution. J Am Board Fam Med. 2013;26(3):239-240. 